\title{
perifèria
}

Número 20(2), diciembre 2015

http://revistes.uab.cat/periferia

\section{No sense la meva música: la música com a fet social}

\author{
Josep Martí, IMF-CSIC, Barcelona ${ }^{1}$
}

DOI: http://dx.doi.org/10.5565/rev/periferia.495

\section{Resum}

Tot reconeixent que la societat no és la mera suma d'individus sinó el resultat d'individus interactuant, i els individus són així mateix el resultat de la seva interacció, l'article pren com a punt de partença la idea que aquesta interacció que ens construeix com a individus es produeix entre d'altres molts recursos mitjançant la música. La importància que té la música a la tasca de fer societat es posa especialment de manifest en el paper que juga en tres paràmetres bàsics de la lògica social: la identitat, l'ordre social i la necessitat de l'intercanvi. Però no és tan sols que la persona sigui incomprensible sense el constant intercanvi amb altres individus; sense moltes de les coses que l'envolten, ontològicament, tampoc podria ésser. I la música, en aquest sentit, en tant que tecnologia, pot arribar a entendre's així mateix como una veritable extensió del nostre cos (McLuhan).

Paraules clau: música, societat, individu, situació, cos

\begin{abstract}
Knowing that society is not a mere sum of individuals but the result of interacting individuals, and individuals are also the result of this interaction, this article draws from the idea that this interaction, that construct us as individuals, happens also through music. The importance that music has in the process of making up a society is clearly brought to light in the role that it plays in the three basic parameters of the social logics: identity, social order and the need for exchange. But it is not only that we as individuals would be incomprehensible without the constant exchange with other people. Without many of the things that surround us, we ontologically could not be. And in this regard, music, as technology, can be also conceived as a real extension of our body (McLuhan).
\end{abstract}

Keywords: music, society, individual, situation, body

Sabem que en antropologia hi ha dos conceptes clau: cultura i societat, dos conceptes que de fet no es poden entendre l'un sense l'altre. I si a l'antropologia li interessa la música i pot fer importants aportacions al seu estudi és precisament perquè música és cultura i al mateix temps és un fet social. En aquest article em cenyiré al vesant social de la música.

$1 \quad$ Enviar correspondencia a: jmarti@imf.csic.es 


\section{perifèria}

Número 20(2), diciembre 2015

http://revistes.uab.cat/periferia

A l'encarar la problemàtica relativa a societat vers individu, sovint s'afirma i amb raó que en realitat es tracta d'una falsa dicotomia. Atès que no resulta imaginable aquestes dues realitats separades, més adient és parlar de "dualitat". No hi ha individu sense societat ni societat sense individus. L'individu aïllat de l'entorn és una mera abstracció, i la mateixa idea de societat mancaria de sentit si no tinguéssim en compte els individus. Tot això ens duu a la següent idea que és la que es troba subjacent en aquest article: Ens equivoquem si pensem que som individus "individuals", amb tot el que impliquen aquests termes. Som "fragments", parts d'un tot. El que som ho som en i amb els altres. Cadascun de nosaltres és el resultat d'innombrables interseccions amb una miríade de trajectòries de moltes persones. Si ens creiem individuals és sobretot per ideologia, de qualsevol tipus: social, política, religiosa... Però això que anomenem "jo" o "nosaltres" són de fet fragments, o dit d'una altra manera, resultat de la interacció ${ }^{2}$ no tan sol amb altres individus sinó amb tot allò que ens envolta.

Individu i societat constitueixen dos aspectes diferents de la realitat però cadascun d'ells sense condició d'entitat pròpia, una realitat conformada per espais d'interconnexions en els quals emergeixen els individus. Per tant, la primera idea que voldria destacar és que una societat no és la mera suma d'individus. Una societat és el resultat d'individus interactuant, i els individus són així mateix el resultat d'aquesta interacció. I aquesta interacció es produeix entre d'altres molts recursos mitjançant això que entenem per música.

La importància que té la música en la tasca de fer societat es posa especialment de manifest en el paper que juga en tres paràmetres bàsics de la lògica social: la identitat, I'ordre social i la necessitat de l'intercanvi. Aquests paràmetres són

2 Al llarg d'aquest text sempre que parli d'"interacció ho faig més aviat en el sentit d'"intraacció". Barad distingeix "intra-acció" d'"interacció". Quan parlem d'"'interacció" ens referim a una relació entre dues agències preconstituïdes abans d'iniciar la interacció. La "intra-acció", en canvi, implica la mútua constititució d'agències que emergeixen mitjançant la seva intra-acció (Barad 2007: 33). 


\section{perifèria}

Número 20(2), diciembre 2015

http://revistes.uab.cat/periferia

consubstancials a la natura social de l'ésser humà. La identitat és allò que ens defineix dins d'una comunitat i ens delimita dels altres. El fet que els individus siguem éssers socials comporta l'organització i l'ordre social. I la lògica de la necessitat de l'intercanvi té a veure amb la realitat de què els individus només poden sobreviure si articulen de manera convenient relacions d'intercanvi amb altres membres de la societat. I les pràctiques musicals tenen molt a dir sobre qui som, com es pensa que som o com ens construïm, sobre el lloc que ocupem a la societat, como entenem l'ordre social i com interactuem en l'intercanvi de prestacions. La música no és merament quelcom sobre allò que és social sinó que es vida social, quelcom capaç d'estructurar la experiència social (DeNora 2002: 19).

A principis de 2015, quan tot just estava preparant aquest text, Ibrahim, un noi de poc més de vint anys m'explicà l'anècdota següent: Un dissabte a la nit conduïa el seu cotxe amb tres dels seus amics, i talment com feia habitualment tenia la radio encesa. Era l'hora de la sortida de les discoteques i de sobte un control de policia els fa aturar. Baixa la finestreta, i l'agent, després de fer una ullada a l'interior de l'automòbil, els deixa marxar sense demanar la documentació ni sotmetre al conductor al sovint temut control d'alcoholèmia. La interpretació d'Ibrahim fou de què si se'ls va deixar anar sense fer cap tipus de control fou senzillament perquè en aquell moment, casualment, l'emissora de ràdio emetia música clàssica. Amb un altre tipus de música -em digué- segur que ens haurien fet el control.

Fos aquesta o no la raó per la qual l'agent de policia no fes cap tipus de control, el fet de què es pensés en aquesta possibilitat ja és ben indicatiu. La música -com a "actant" (Latour 2008))- hauria condicionat el comportament de l'agent. Aquesta anècdota és suficientment suggeridora com per estimular algunes reflexions sobre la música i el fet social.

La primera d'aquestes reflexions té a veure amb la capacitat de la música de suggerir identitats. Admetent que les suposicions d'Ibrahim fossin correctes, I'agent de policia va deduir pel tipus de música que s'escoltava al cotxe que els seus 


\section{perifèria}

Número 20(2), diciembre 2015

http://revistes.uab.cat/periferia

ocupants res no tenien a veure amb aquells joves eixelebrats que no els importa agafar el volant malgrat tenir el cos literalment amarat d'alcohol. El tema música i identitat és un tema recurrent a la literatura musicològica de les darreres dècades ${ }^{3}$. D'entrada, podem pensar que si hi ha músiques que agraden, si hi ha músiques que refusem o àdhuc menystenim, si hi ha músiques que resulten cares, si hi ha músiques que hom considera autèntiques o no, són qüestions que tenen molt a veure amb identitat.

Escoltem música perquè ens agrada. Però també l'escoltem perquè ens reflectim en ella mitjançant les significacions i valors que li atorguem. Ens identifiquem amb ella, i performant com persones musicals (Auslander 2006) ens construïm i/o reforcem les nostres identitats. Sovint, quan es parla de música i identitat s'empra aquest darrer terme de forma vaga o molt genèrica tot fent-lo coincidir fins i tot amb qüestions com la dels gustos musicals. Una cosa és que una música agradi i una altra que ens identifiquem o que se'ns identifiqui amb ella. Pròpiament parlant, doncs, si associem música i identitat és perquè atorguem valor representacional a aquesta música. És aquella música que, socialment, s'entén com pròpia d'una identitat, ja sigui aquesta col-lectiva o individual, tenint a més en compte que són diverses las identitats que confereixen personalitat a un mateix individu. Això és el que succeí en l'exemple esmentat d'aquells joves. L'agent va associar el tipus de música que s'escoltava amb un tipus de personalitat en absolut sospitosa d'ésser tan irresponsable com per fer anar el cotxe amb més copes de les permeses.

Actualment tots coincidirem més o menys en què és el model processual el que més ens satisfà per entendre la problemàtica de música i identitat. Les pràctiques musicals juguen un paper actiu en la construcció, negociació i transformació de les identitats (Born i Hesmondhalgh 2000: 31). A nivell individual es pot entendre la música com una tecnologia del jo, un recurs per a la constitució -sempre en procésdel jo i que contribueix per tant a la construcció i manteniment de la identitat a la vida quotidiana (DeNora 2000: 47). Però a nivell de percepció social, aquell vell 


\section{perifèria}

Número 20(2), diciembre 2015

http://revistes.uab.cat/periferia

model homològic en el seu dia desacreditat amb raó per mecanicista i determinista (Born i Hesmondhalgh, 2000: 31) continua essent d'alguna manera vàlid, almenys per explicar percepcions com la del policia que aturà l'automòbil de l'Ibrahim.

Els individus desenvolupen un sentit d'identitat a partir de la interacció amb els altres (Blumer 1969 a Schneider 2010: 7). El jo és al mateix temps individual i interaccional. Per això, lluny de concebre la identitat com una essència, qualsevol identitat d'una persona en un moment donat és el resultat del contacte mantingut amb moltes altres trajectòries personals, totes aquelles amb les quals ha anat interactuant al llarg de la vida. De fet performem les nostres identitats, i la mateixa idea de performance implica un joc dialèctic entre el que actua i el o els davant dels quals s'actua, de manera que aquestes interaccions contribueixen a configurar les identitats. En el sistema en el qual es mou l'ésser humà, la subjectivitat és emergent més que no pas donada, és distribuïda més que localitzada solament a la consciència (Hayles 1999: 291).

La interacció amb els altres és, doncs, un element determinant per a la construcció identitària, sense oblidar nogensmenys que el nostre sentit de qui som és a més funció de la nostra relació amb l'espai, el temps, la nostra acció i experiència, i els objectes del nostre entorn (Rosa 2013: 145). La música forma part d'aquest entorn, i entenent-la com "actant", podem estar segurs que cogenera les nostres identitats, i més avui en què per les possibilitats tecnològiques, mai com ara ens hem trobat tan contínuament immersos en fluxos sonors de tot tipus.

En part, performem les nostres identitats mitjançant la poderosa tecnologia de la música. I quan parlem de "tecnologia" no se I'ha d'entendre com quelcom que simplement s'afegeix al cos des de fora. És quelcom que se li incorpora i ensems modifica qualitativament (Manning 2007: xxii). No oblidem que talment com escrigué Jenny Sundén (2015), "Far from being natural, pre-technological, or in any sense pure, bodies are on a fundamental level technologically produced". Això és el 


\section{perifèria}

Número 20(2), diciembre 2015

http://revistes.uab.cat/periferia

que fa que puguem entendre l'ésser humà com a criatura protèsica (Wolfe 2009: $X X V)$.

En tant que éssers socials, ens organitzem i generem ordre social, entès com les formes d'estructuració de les relacions socials, com un conjunt de regles, normes i valors que proporcionen una certa estabilitat al sistema social. Es tracta d'aquelles assumpcions cognitives compartides socialment que es donen per fet sobre la realitat del món social (Mouzelis 2008: 15). Aquest ordre social, entre d'altres coses, regeix les relacions entre els diferents estrats d'una determinada societat i, per tant, també les relacions de tipus jeràrquic que s'estableixen. De la mateixa manera que succeeix amb la identitat, el paper que la música juga en aquest ordre social no és merament el de reflectir-lo sinó també el de contribuir a la seva creació i manteniment. De fet, música i ordre social es troben en una relació de mútua coproducció (DeNora 2003: 38).

En un altre treball ja vaig fer esment a la importància que a occident atorguem a aquesta tripartició del nostre univers musical: parlem de "música clàssica", "tradicional" i "popular" (moderna) (Martí 2000: 221 i ss.), que no casualment es correspon a dos dels principals motors que han mogut la nostra societat en els darrers segles: la lluita de classes i els nacionalismes. No repetiré ara el que digué aleshores sinó que em limito a recordar-ho perquè em sembla un bon exemple d'aquesta estreta imbricació entre música i ordre social. Els límits establerts en aquesta tripartició separen no només perquè es puguin correspondre amb algunes dades objectives de la realitat ans també perquè atorguem a aquestes línies demarcadores uns continguts d'acord amb les nostres necessitats de fer prevaldre determinats valors socials. Les categories "culte", "tradicional" i "popular" formen part de l'ordre social.

El poderós univers simbòlic amb el qual dotem a les pràctiques musicals constitueix un eficaç instrument per construir, mantenir o també, naturalment, per modificar o destruir aquest ordre social. Mitjançant la música s'ha contribuït a construir ordres 


\section{perifèria}

Número 20(2), diciembre 2015

http://revistes.uab.cat/periferia

socials nacionals, de classe, de gènere... I a través de la música també se subverteix aquest ordre social. Durant l'esclavisme, el fet de què els esclaus a Amèrica "tinguessin música" fou, per exemple, un argument esgrimit pels abolicionistes per advocar per la humanitat que se'ls negava i subvertir per tant aquell ordre social que justificava la seva explotació (Cruz 1999: 159). Els exemples que podríem aportar en aquest sentit són inexhauribles, però a manca d'espai basta recordar el que amb tant d'encert escrigué Jacques Attali: "amb la música va néixer el poder i el seu contrari: la subversió" (1978: 15).

Ordre social és un concepte molt ampli. Si a nivell macro es pot afirmar que la música contribueix a crear i mantenir un ordre social, també és fàcil apreciar la seva importància en situacions concretes d'interacció social. La música, per tot allò que pot arribar a connotar, és capaç d'implementar determinades regulacions, normes i valors en una situació donada. És al que ens referim d'una o altra manera quan diem que la música "crea" ambients. Tal com ens diu Tia DeNora, la música és aquell tipus de material cultural mitjançant el qual es construeixen escenes que regulen i estructuren situacions d'interacció social (2004: 110), escenes que permeten o faciliten determinats tipus d'agència, diferents tipus de fruïció i modes d'ésser o estar (ibíd.: 123). En aquest sentit, la música és un més d'aquells elements que constitueixen el tool kit (Swidler, 1986: 273) per dotar de sentit a situacions de la vida quotidiana, quelcom que es posa especialment de manifest en l'ús que fem de les músiques ambientals.

Crec que ens podem acostar més a aquesta dimensió funcional de la música si ens servim de categories analítiques que donin la deguda importància a la situacionalitat. En parlar de música i ordre social resulta especialment pertinent pensar en el fet de què no és només el flux sonor allò que juga un paper important sinó la situació en la qual es produeix i la situacionalitat que àdhuc podem dir que es crea mitjançant les pràctiques musicals. Tot tornant ara a l'anècdota del principi, la imatge de quatre xicots al cotxe i lliurats a l'escolta musical em sembla particularment potent; sabem que I'automòbil és realment un espai escaient per a això. La moderna tecnologia permet una qualitat de so excel·lent, i l'aïllament de la 


\section{perifèria}

Número 20(2), diciembre 2015

http://revistes.uab.cat/periferia

cabina facilita el gaudi de la música en un volum elevat, cosa que no sempre és possible a casa ${ }^{4}$. I aquesta imatge dels quatre nois tancats al cotxe i immersos en un flux sonor ens porta fàcilment a la idea del "sonòtop", un concepte que adaptat a les necessitats del musicòleg li pot ser d'ajut.

Parlar de "sonòtop" significa moure's dins del context conceptual del soundscape que ens fa pensar en com el medi acústic és percebut, entès $\mathrm{i}$ interpretat. Un paisatge sonor és, doncs, un constructe perceptual i al mateix temps un fenomen físic (Farina, 2014: 4); implica doncs tant una realitat subjectiva com objectiva. De

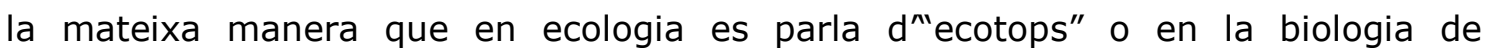
"biòtops", podem parlar de "sonòtops". Un sonòtop es pot definir com la totalitat de sons que es produeixen en un moment i lloc determinat, ja siguin geofonies, biofonies o antropofonies (Farina, 2014: 1). Un sonòtop és concebible com a sistema i com a tal pressuposa diversos elements que interaccionen, així com també propietats emergents.

Qualsevol esdeveniment musical es pot conceptualitzar com formant part d'un sonòtop en el que entre altres possibles fluxos sonors detectables es produeixen antropofonies d'índole musical. En el cas dels xicots al cotxe, la música procedent de la ràdio compartiria l'espai amb la fressa del motor, les eventuals converses dels passatgers, el soroll de l'exterior, etc.

Un concert es pot conceptualitzar com a sonòtop. A més de la interpretació musical de I'orquestra, aquest sonòtop està constituït també per altres elements sonors: la tos del públic, els aplaudiments, els bravos, el soroll que es fa al desembolicar el caramel, el respirar d'una persona d'edat que tenim al costat, el maleït mòbil que sona en el moment menys oportú, el xiuxiueig irrespectuós d'algú de prop... tota una sèrie de sons que aconsegueixen el seu màxim reconeixement en la coneguda peça 4'33" de John Cage. 


\section{perifèria}

Número 20(2), diciembre 2015

http://revistes.uab.cat/periferia

La manera com aquests diferents sons que comparteixen situació amb la principal font acústica (música pròpiament dita) són entesos i valorats és força indicativa de la significació i ús social de l'esdeveniment musical en qüestió. L'equilibri dels diferents fluxos sonors que es dóna en un sonòtop pot ésser molt diferent segons I'esdeveniment musical del qual es tracti. Comparem un concert a l'auditori amb un recital de pop en un gran estadi, el concert d'una banda local al carrer en el curs d'una festa major, el bar musical en el qual hi ha una actuació en viu... El control, tolerància o voluntarietat d'emissió de sons secundaris, és a dir, els no explícitament musicals, no és la mateixa en els diferents exemples suara esmentats, i això té a veure amb molts dels múltiples aspectes que preocupen al musicòleg: el model d'escolta, la significació atorgada a l'esdeveniment i al tipus de música que es desenvolupa a l'escenari, la relació que s'estableix entre músics i audiència, etc. Un concert de rock seria inconcebible sense els sons generats per l'audiència i que s'experimenten com imprescindibles per vehicular la comunicació fàtica entre músics i públic. En els exemples esmentats, la música constitueix l'element sònic dominant. Però la mateixa peça d'Albinoni executada en un concert, en altres tipus de sonòtops pot perdre el tret d'element sònic dominant tot passant al de secundari o complementari, tal com succeeix en el cas de les músiques ambientals. Per això, en aquells sonòtops en els quals es produeix música, podem parlar en relació a ella de centralitat absoluta (concert), compartida (festa, bar musical) o inexistent (música ambiental) (Martí 2009: 165), diferents possibilitats que juguen amb la bidimensionalitat del camp auditiu de la qual parla Don Inde (2007: 98): embolcallament i direccionalitat.

La idea de sonòtop aplicada al nostre camp d'estudi, més enllà dels intrínsecs valors estètics de la música, ens ajuda a conceptualitzar-la com aquest magma, aquesta força que inunda un espai, l'omple i crea relacions de cosubjectivitat entre les persones que l'ocupen. Imaginem-nos que estem al tren a primeres hores del matí embeguts en la lectura o potser escoltant música amb els auriculars. De sobte, algú no gaire allunyat d'on som, comença a tocar la guitarra i a cantar amb veu cridanera. Segur que no és la millor hora del dia per escoltar-lo. A partir d'aleshores 


\section{perifèria}

Número 20(2), diciembre 2015

http://revistes.uab.cat/periferia

la situació canvia radicalment. Ens sentim literalment absorbits per la situació, sense desitjar-ho. No podem continuar llegint o prestant la deguda atenció a la nostra música. Ens veiem forçats a sentir l'inesperat cantant bé que intentem no escoltar-lo. Ens veiem dins, sense voler-ho, d'una bombolla sonora; hi ha quelcom de violència en això. El cantant contribueix a generar cosubjectivitat entre els passatgers que es troben dins d'aquella bombolla sonora, una cosubjectivitat que esdevé intersubjectivitat quan s'intercanvien mirades d'amoïnament entre ells. El guitarrista conclou les seves dues cançons i sense pronunciar paraula passa per davant dels passatgers gorra en mà per recollir les monedes que puguin caure. Això em força a posicionar-me. Li dono diners? Si no ho faig no m'acabo de sentir a gust. Però si ho faig tampoc, doncs al capdavall se m'ha imposat una situació que jo no havia cercat i que m'ha impedit continuar amb la meva música o lectura. La actuació musical d'aquell guitarrista en el tren generà una situació.

El concepte de sonòtop -per definició- està relacionat amb el d'espai, que ens interessarà tenir així mateix en compte no només per raons acústiques sinó molt especialment per les de caire expressiu. L'espai on té lloc l'esdeveniment musical constitueix un important metamissatge, important per entendre què és el que s'hi produeix i per reforçar la funció estructurant de l'esdeveniment en relació a l'ordre social. Una de les utilitats de servir-se de conceptes com el de "sonòtop" rau en què ens convida a posar en relació elements constitutius de les pràctiques musicals que amb altres tipus d'enfocaments possiblement no tindríem en compte. A més, ens permet donar el merescut valor heurístic a la situació com unitat discreta d'anàlisi. I d'acord amb el situacionalisme metodològic, el gran valor epistèmic de les situacions rau en què difícilment podem arribar a entendre fenòmens socials en general sense prendre en consideració els comportaments en situacions concretes (Knorr-Cetina 1988: 22). És en situacions concretes on tenen lloc les pràctiques, és a dir, les accions, i ja sabem que la major part del coneixement cultural s'emmagatzema en accions més que en paraules (Hastrup en Carlson 1996: 27).

El filòsof Don Ihde, cercant explicacions del perquè la gent jove es distanciava de la música clàssica, explica que segons li deien els entrevistats, mentre que a la 


\section{perifèria}

Número 20(2), diciembre 2015

http://revistes.uab.cat/periferia

música clàssica se l'entén com "head music" -música mental- les músiques populars s'experiencien com "body music", música corporal. Amb això es juga òbviament amb aquelles dues raons diferenciades a les quals s'associa el gaudi musical, la de la significació referencial que acompanya a la música, l'expressió més acusada de la qual seria la idea adorniana d"escolta estructurada" i la de caire hedonista que fa referència especialment al plaer que se sent en el cos. Però cal tenir molt present que, de fet, la diferència entre unes o altres músiques no està tant en llurs propietats sonores intrínseques ans en el frame (Goffman) en el qual s'emmarquen i que determina la situació. De la mateixa manera que tal com escrivia Paulo Freire (2005: 109) "els éssers humans són perquè estan en situació" podem dir que la música és perquè està en situació. El mode de servir-se de la música depèn de la situació que se li adscrigui. Els concerts de Brandenburg de Bach es presten tant a una escolta mental com a una escolta corporal, i el mateix podem dir de Pink Floyd. La situació ens dóna claus decisives per experienciar la música d'una o altra manera. Sols cal recordar al respecte l'èxit que tingué a Espanya a la dècada dels noranta el cant gregorià dels monjos de Silos que, rere les vendes de milions d'exemplars de discs, durant un cert temps arribà fins i tot a sonar com a música de ball en discoteques, una situació, doncs, completament diferent a la que habitualment s'associa a la pràctica d'aquest tipus de música.

Si l'ordre social constitueix una lògica conseqüència de la natura social de l'ésser humà, una altra lògica social es la necessitat de I'intercanvi, entenent "intercanvi" en el sentit més ampli del terme. Dins d'un món constituït tot ell per agències (Pickering 1995: 6), intercanviem béns, però també experiències, idees, sentiments, carícies, mirades... No és doncs només que l'individu no pugui sobreviure sense intercanviar béns materials, tampoc ho podria fer sense tots aquells tipus d'intercanvis que es corresponen amb necessitats que són de fet les que defineixen la nostra humanitat. Si a l'apartat anterior ens centràvem en l'estructura, en aquest posem l'èmfasi en la relació, en la textura social. Els éssers humans han d'articular de manera convenient per a ells les relacions d'intercanvi 


\section{perifèria}

Número 20(2), diciembre 2015

http://revistes.uab.cat/periferia

amb altres membres de la societat ${ }^{5}$, quelcom que emfatitza de manera molt especial la perspectiva mutualista: "les persones fan coses amb, per i en relació amb els altres, emprant mitjans que podem descriure [...] com culturals" (Carrithers 1995: 58). Entre aquests mitjans, la música ocupa sens dubte un lloc important.

La relació que podem establir entre música i la dinàmica de l'intercanvi entre les persones pot ser molt diferent. En el primer que pensem és que la música en sí mateixa constitueix un objecte d'intercanvi. Com qualsevol altre producte cultural, l'especialista fa ús de les seves capacitats podent obtenir quelcom a canvi, des del simple reconeixement fins a remuneració econòmica. Això ha estat sempre així i sense que faci falta incidir-hi per l'obvietat, actualment a Occident parlem de les poderoses indústries culturals, en les quals la música juga un paper cabdal.

Un segon punt també ben entenedor és que la música facilita la dinàmica de I'intercanvi. Aquesta és una conseqüència directa del valor estructurant de la música en situacions, tema que ha centrat la nostra atenció en I'anterior apartat. La música és tant conseqüència com motor de sociabilitat. El fet de compartir una música determinada en una situació en concret, per exemple en el concert o en el cas esmentat del guitarrista al ferrocarril, ajuda a crear espais de cosubjectivitat el que òbviament facilita la intersubjectivitat i, per tant, contribueix a satisfer la necessitat de l'intercanvi. Actualment es reconeix el paper que juguen les emocions en les dinàmiques d'intercanvi social (Lawler 1999), i ben sabut és l'alt potencial de la música per expressar, vehicular i generar emocions.

Però a més d'aquests dos aspectes, cal prendre també en consideració que la música es constitueix ella mateixa per l'intercanvi. La idea d"'audiència", tal com reconeixen els estudis sobre performance, és essencial per entendre les pràctiques musicals. Podem afirmar que la música s'implementa en l'altre. En qualsevol

5 La teoria de l'intercanvi social sorgí precisament arran d'aquesta idea bàsica (Cook 1987). 


\section{perifèria}

Número 20(2), diciembre 2015

http://revistes.uab.cat/periferia

performance, la música produïda cal entendre-la en part com el resultat de l'acció del músic sabent-se escoltat. No es balla o canta de la mateixa manera davant d'un públic que omple la sala que quan son minses les butaques ocupades.

Entendre la música com a performance implica haver de considerar-la irreductiblement com a fenomen social (Cook 2003: 206). Si aquest interès per la performance constitueix un bon antídot contra tota temptació de reificar l'obra musical, serveix també per destacar el valor que té la música per a la interacció humana. Tinguem present que quan parlem de "performance" no ens referim simplement al fet de reproduir un text (musical). Dins dels estudis sobre performance, allò que interessa prendre en consideració no és només la "performance de quelcom" sinó d'aquest quelcom "com a performance" (Cirino 2005: 88-87), que no és precisament el mateix. Performance implica sempre interacció. John Cage, parlant de la seva peça 4'33" digué:

\footnotetext{
"Most people mistakenly think that when they hear a piece of music that they're not doing anything but that something's being done to them. Now this is not true and we must arrange our music, we must arrange our art, everything, I believe, so that people realise that they themselves are doing it and not that something is being done to them." (Nyman 1974: 21)
}

Així, doncs, la música és objecte d'intercanvi, facilita l'intercanvi, i la mateixa música és, en part, producte d'intercanvi. Però fins $i$ tot podem anar més enllà i abordar un tema ontològicament més pregon, que tot i que és quelcom que es mereix una major elaboració no puc evitar la temptació de plantejar-lo: No és només que jo com individu no pugui sobreviure sense aquest constant intercanvi amb els individus que m'envolten. És també que sense moltes de les coses que ens envolten, ontològicament, aquest jo no podria ésser. 


\section{perifèria}

Número 20(2), diciembre 2015

http://revistes.uab.cat/periferia

Pensem per un moment, qui soc jo? Si perdo un dit, un braç, continuo essent jo? Si perdo el cor i me'l reemplacen per un d'artificial, continuo essent jo? Si fóssim manllevant progressivament fragments al cos acabaríem en quelcom irreductible: la consciència. Som consciència. Però realment som això? De fet només som quan ens implementem, quan actuem. La música que no sona no és música. La dona que no performa feminitat no és dona, de la mateixa manera que I'home tampoc ho és si no performa masculinitat. I els éssers humans, com ens implementem? Ens implementem amb el cor, amb el braç, amb els dits... tot això són extensions d'aquest nucli irreductible que és la consciència. Però a més, ens implementem també amb aquests objectes que constitueixen així mateix extensions del nostre cos. I entre tots aquests elements del món que ens envolta en els quals ens implementem també està òbviament la música.

La idea principal és que podem establir un contínuum ontològic entre la consciència individual i tot allò que fa que ens implementem. Ja sé que el nostre sentit comú ens fa veure les coses de manera diferent. Les nostres ideologies ens fan entendre com a I"homo clausus" que criticava Norbert Elias (1982), quelcom que en certs nivells de la realitat pot resultar pràctic, de la mateixa manera que en certs nivells de la realitat optem per fer com si la terra fos plana o esfèrica quan sabem que no és ni una cosa ni l'altra. I el mateix succeeix amb la noció d"individu". El nostre sentit comú ens fa veure els individus com realitats absolutes, i de fet complicaríem molt la nostra vida quotidiana si no ho féssim així. Què seria del Iliure albir, la responsabilitat social, les teories de la salvació religiosa o àdhuc de la societat de mercat? Què seria d'aquest jo neoliberal sotmès a tècniques d'optimització personal al servei de la producció? Ara bé, constitueixen realment els individus realitats absolutes?

Totes les tecnologies que emprem són extensions del nostre sistema físic i nerviós (McLuhan 1994), i la música, com a tecnologia, en situacions determinades, pot ésser doncs concebuda així mateix com una extensió del nostre cos. Talment com escrivia Ivanov (2008: 241), utilitzant eines i instruments en la nostra activitat conscient resulta en l'expansió cultural de l'individu, de manera que la consciència 


\section{perifèria}

Número 20(2), diciembre 2015

http://revistes.uab.cat/periferia

s'implementa no només en el cervell i la resta del cos sinó en les diferents coses materials que envolten I'activitat humana, allò que forma el cos no orgànic de cada persona.

Això ho podrem entendre millor si reflexionem sobre la problemàtica de l'escolta. Sabem que n'hi ha diferents models, des de la denominada "escolta distreta" en la qual es presta una minsa atenció a la música fins aquelles que suposen una major implicació per part de l'oient. Sóc conscient de què la qüestió de l'escolta és realment complexa però des del punt de vista experiencial podem determinar-ne dos tipus bàsics. Aquella escolta que en termes molt generals podem entendre com de tipus contemplatiu en la qual amb més o menys concentració fixem la nostra atenció en l'execució musical i aquell model d'escolta mitjançant el qual ens deixem endur per la música.

El primer tipus d'escolta el podem emmarcar dins d'aquella ontologia de tipus dualista a la que també s'ha denominat de "dominació" (Pickering 2008). Aquí es conceptualitza la música com quelcom extern i objecte de les nostres reflexions i apreciacions, potser fins i tot podríem dir que es correspon amb la dimensió de la Erfahrung des del punt de vista fenomenològic. En canvi, el segon model es correspondria més aviat amb I'ontologia de l'esdevenir (Pickering 2008): aquí ens fonem amb la música, la música esdevé nosaltres o nosaltres esdevenim música. Per una part percebem l'estímul sonor, per l'altra part el sentim. Per una part podem parlar d'Erfahrung, por l'altra d'Erlebnis. Dualitat vers unitat.

Talment com afirma Pickering (2008: 13), "if dualist detachment and domination is still our natural ontological attitude, it is because since the Industrial Revolution we have remade the material world to make it so". Però això no significa que I'ontologia de l'esdevenir no sigui també perfectament apropiada per entendre la nostra realitat. De fet, podem constatar fàcilment la validesa d'aquestes dues ontologies diferenciades en la realitat del nostre món: La medicina al·lopàtica vers I'homeopàtica. L'activitat sexual entre dues persones es pot experimentar com acte 


\section{perifèria}

Número 20(2), diciembre 2015

http://revistes.uab.cat/periferia

de dominació d'un cos sobre l'altre o com un moment en el qual ambdós es fonen. A la divinitat se li pot retre culte i veure-la com quelcom molt allunyat o l'individu pot arribar a fondre's amb ella tal com és propi de tants moments místics, en una experiència hipostàtica. Amb la música passa exactament el mateix. Se la pot experimentar com quelcom extern, que es reconeix, s'usa, es gaudeix, s'analitza, fa pensar... o bé un mateix se sent diferent perquè vibra al uníson amb ella. Aleshores és quan esdevenim música:

With sounds - as with ambiances - we do not experience the world from the outside, in front of us, but through it, in accordance with it, as part of it. The sensing subject is nothing but a resonant body that gets in tune and in sync with his environment. [...] In a way, I become part of what I sense (Thibaud 2011).

Avui parlem de "música" en abstracte com si això fos el mateix que fa dos-cents anys enrere, i res més lluny de la realitat. La relació que avui tenim amb la música és completament diferent. Abans deia que la idea de situació ens resulta imprescindible per entendre el que implica la música per a l'ésser humà. El gran canvi radical que s'ha anat produint en les darreres dècades és que la música s'ha alliberat de la situació (el que no significa pas que no es doni sempre en una situació concreta). Música ja no és allò que hom podia escoltar només en determinades situacions. Avui, gràcies als avenços tecnològics, la música es un recurs més de vida. Es pot escoltar la música que més vingui de gust, en la situació triada i en el moment més desitjat. La tenim al saló de casa, a la cuina, i el despertador ens fa aixecar del llit amb ella. Tenim música a les oficines, restaurants, comerços i àdhuc als ascensors; quan anem en cotxe o a peu, gràcies al walkman, la manifestació més evident de la criatura protèsica que som. La societat ha creat i desenvolupat poderoses tecnologies musicals i mediàtiques, i aquestes, en qualitat d'actants han fet possible l'emergència d'un nou subjecte caracteritzat per l'escolta musical omnímoda, és a dir, amb una disponibilitat musical total. A aquest nou subjecte se li ofereix la possibilitat d'implementar-se en la música com mai abans havia estat el cas. Això és el que facilita enormement que 


\section{perifèria}

Número 20(2), diciembre 2015

http://revistes.uab.cat/periferia

la música es constitueixi en una extensió més del meu cos; en aquest sentit la música esdevé jo. Però a més, aquestes extensions del meu cos constitueixen al mateix temps elements estructurants del complex entramat social. Mitjançant aquestes músiques el jo esdevé també societat. Recordem el que escrivia Josh Kun (2005: 3): "A song is never just a song, but a connection, a ticket, a pass, an invitation, a node in a complex network". Amb les músiques que jo mateix em programo, creo i reforço lligams de pertinença a múltiples comunitats semiòtiques. I amb les que em programen, com és el cas de les músiques ambientals, se'm recorda que algú o quelcom és allà pensant en mi, amb les finalitats que siguin; es tracta d'una comunicació fàtica que també serveix per fer-nos recordar qui posseeix el control sobre aquella situació en la qual jo soc un mer transeünt (Martí 2009).

\section{CONCLUSIONS}

El darrer punt ens ha servit per insistir en la necessitat de defugir de la idea d'individu com homo clausus, i d'aquesta manera acabo el text de la mateixa manera com I'havia començat, tot emfatitzant la natura social de l'individu. A tall de conclusions voldria destacar els següents aspectes:

1. Si l'individu resulta incomprensible sense prendre en consideració la seva natura social, el mateix podem afirmar de les seves produccions culturals. Tota producció cultural és un fet social i cal saber veure l'agència que es deriva de les mútues interseccions entre aquestes produccions i els individus (Urry 2000: 18).

2. La relació de la música amb paràmetres de lògica social com la identitat, l'ordre social i la necessitat de l'intercanvi es materialitza en la situació. Sabem que la música no té significats intrínsecs car li són atorgats socialment però és en la implementació de les pràctiques musicals en la situació que una música significa quelcom i té un paper determinat en la vida social de l'individu. 


\section{perifèria}

Número 20(2), diciembre 2015

http://revistes.uab.cat/periferia

3. Del darrer punt s'infereix la importància de la situació com unitat heurística, és a dir, el marc on tenen Iloc actes performatius, on es produeix l'acció.

4. Hi ha moltes maneres d'abordar l'estudi de la música, i ens n'ocupem tant des de diferents disciplines com també des de la interdisciplinarietat. Sabem que la base del coneixement rau en saber relacionar; relacionar diferents elements de forma pertinent i rellevant per a la recerca. Per tant, podem pensar que canviant la constel-lació d'elements a relacionar podrem arribar a obtenir nous coneixements. Enfocar la música des d'una perspectiva diferent equival a pensar la música de manera diferent. Al llarg d'aquest text he introduït algunes perspectives que ens conviden a això com, per exemple, pensar la música des de la perspectiva dels sonòtops o també entendre-la com una extensió més del cos humà.

5. Un ensenyament que podem obtenir de la història de la musicologia és que entre els seus diferents fils evolutius està aquell que consisteix en descentrar de manera progressiva l'objecte d'estudi. En un principi, en nom de la musicologia comparada, folklore musical o després etnomusicologia hom centrava l'atenció en el text, lògica conseqüència dels orígens de la musicologia, estretament lligats a la filologia i la literatura. Especialment a partir d'Allan P. Merriam es començà a parlar de l'interès d'estudiar la música en la cultura, i també como a cultura. Ja interessava doncs quelcom més que l'estricte text musical. Després, als anys 80 començà a adquirir rellevància la dimensió performativa. Amb això interessava el text i el context però també especialment com aquest text tenia lloc a l'escenari, és a dir, el text com a performance. Amb la idea de "sonòtop" anem una mica més enllà, tot descentrant encara més el primitiu objecte d'estudi: la música.

6. Un altre alliçonament que també ens dóna la història és que progressivament hem anat descentrant la perspectiva de l'investigador. Hom ha esdevingut conscient de l'eurocentrisme, l'etnocentrisme, l'androcentrisme, i els nostres esforços per superar aquestes visions tergiversades de la realitat han menat a una indubtable millora de la 


\section{perifèria}

Número 20(2), diciembre 2015

http://revistes.uab.cat/periferia

nostra pràctica científica. Ara, tot bregant per superar la fal-làcia de I"'homo clausus" i en un esperit posthumanista, veiem cada cop més clara la necessitat d'evitar l'antropocentrisme, tant per raons heurístiques com també ètiques i polítiques.

7. I com a darrer punt, em sembla important recalcar la idea de què no és només que hom performi música, ans nosaltres mateixos, com a individus, com a societat, ens performem mitjançant les pràctiques musicals.

\section{BIBLIOGRAFÍA}

Attali, Jacques (1978). Ruidos. Ensayo sobre la economía política de la música. Valencia: Ruedo Ibérico.

Auslander, Philip (2006). "Musical Personae". The Drama Review, 50/1, pp. 100119.

Barad, Karen (2007). Meeting the Universe Halfway: Quantum Physics and the Entanglement of Matter and Meaning. Durham \& London: Duke University Press.

Blumer, H. (1969). Symbolic interactionism. Englewood Cliffs: Prentice Hall.

Born, Georgina i David Hesmondhalgh, (eds.) (2000). Western Music and Its Other. Difference, Representation, and Appropriation in Music. Berkeley: University of California Press.

Bull, Michael (2003). "Soundscapes of the car. A critical study of automobile habitation". En: Michael Bull i Les Back (eds.), The Auditory Culture Reader. New York: Berg Publishers, pp. 357-374.

Carlson, Marvin (1996). Performance: A Critical Introduction. London: Routledge. Carrithers, Michael (1995). ¿Por qué los humanos tenemos cultura? Madrid: Alianza.

Cirino, Giovanni (2005). Narrativas musicais: performance e experiência na musica popular instrumental brasileira. São Paulo: Universidade de São Paulo (tesi doctoral). 


\section{perifèria}

Número 20(2), diciembre 2015

http://revistes.uab.cat/periferia

Cook, Karen S. (1987). Social exchange theory. Newbury Park: Sage.

Cook, Nicholas (2003). "Music as Performance". En: Martin Clayton, Trevor Herbert i Richard Middleton (eds.), The Cultural Study of Music: A Critical Introduction. New York \& London: Routledge, pp. 204-214.

Cruz, Jon (1999). Culture on the Margins. The Black Spiritual and the Rise of American Cultural Interpretation. Princeton: Princeton University Press.

DeNora, Tia (2002). "Music into action: performing gender on the Viennese concert stage, 1790-1810". Poetics, 30, pp. 19-33.

(2003). After Adorno: Rethinking music sociology. New York: Cambridge University Press.

(2004). Music in Everyday Life. Cambridge: Cambridge University Press.

Elias, Norbert (1982). Fundamentos de sociología. Barcelona: Gedisa.

Fabbri, Franco (2013). "Taboo Listening (or, What Kind of Attention?)". En: M. García, A. Kassabian i E. Boschi, Ubiquitous Musics. Surrey: Ashgate, pp. 161-173.

Farina, Almo (2014). Soundscape Ecology: Principles, Patterns, Methods and Applications. Springer Dordrecht: Heidelberg. DOI 10.1007/978-94-007-7374-5

Freire, Paulo (2005). Pedagogy of the Oppressed. New York \& London: continuum.

Hayles, NC. (1999). How We Became Posthuman: Virtual Bodies in Cybernetics, Literature and Information. Chicago: University of Chicago Press.

Ihde, Don (2007). Listening and Voice: Phenomenologies of Sound. Albany: University of New York Press.

Ivanov, Pavel B. (2008). "Consciousness as a Relation between Material Bodies". En: H. Wautischer i R. A. F. Thurman, Ontology of Consciousness: Percipient Action. Cambridge \& London: The MIT Press, pp. 241-272.

Kun, Josh (2005). Audiotopia: Music, Race, and America. Berkeley: University of California Press.

Latour, Bruno (2008). Reensamblar lo social. Buenos Aires: Manantial.

Lawler, Edward J. (1999). "Bringing Emotions into Social Exchange Theory". 


\section{perifèria}

Número 20(2), diciembre 2015

http://revistes.uab.cat/periferia

Annual Review of Sociology, 25, pp. 217-244. DOI: 10.1146/annurev.soc.25.1.217.

McLuhan, Marshall (1994). Understanding Media: The Extensions of Man. Cambridge: The MIT Press.

Manning, Erin (2007). Politics of Touch: Sense, Movement, Sovereignty. Minneapolis \& London: University of Minnesota Press.

Martí, Josep (2000). Más allá del arte. La música como generadora de realidades sociales. Sant Cugat del Vallès: Deriva.

(2009). "Como el aire que respiramos: músicas ambientales en espacios de la cotidianidad". Música Oral del Sur, 8, pp. 163-176.

Mouzelis, Nicos P. (2008). Modern and Postmodern Social Theorizing: Bridging the Divide. Cambridge: Cambridge University Press.

Nyman, M. (1974). Experimental Music: Cage and Beyond. Cambridge: Cambridge University Press.

Pickering, Andrew (1995). The Mangle of Practice: Time, Agency, and Science. Chicago: University of Chicago Press.

(2008). "New Ontologies". En A. Pickering i K. Guzik (eds.), The mangle in practice: science, society, and becoming. Durham: Duke University Pres, pp. 1-14.

Revilla Gútiez, Sara (2011). "Música e Identidad. Adaptación de un modelo teórico". Cuadernos de Etnomusicología,1, pp. 5-28.

Rosa, Hartmut (2013). New Directions in Critical Theory Social Acceleration: A New Theory of Modernity. New York: Columbia University Press.

Schneider, Christopher J. (2010). "Introduction: Music and identity Studies". Symbolic Interaction, 35, pp. 7-10. DOI: 10.1108/S0163-2396(2010)0000035004

Sundén, Jenny (2015)."On trans-, glitch, and gender as machinery of failure".

First Monday, 20/4 - 6, URL: http://journals.uic.edu/ojs/index.php/fm/article/ view/5895/4416 [consultat el 15.2.2015] DOI: http://dx.doi.org/10.5210/ fm.v20i4.5895 


\section{perifèria}

Número 20(2), diciembre 2015

http://revistes.uab.cat/periferia

Swidler, Ann (1986). "Culture in Action: Symbols and Strategies." American Sociological Review , 51, pp. 273-286. DOI: http://dx.doi.org/10.2307/2095521

Thibaud, Jean-Paul (2011). "A Sonic Paradigm Of Urban Ambiances". Journal of Sonic Studies, 1/1, URL: http://journal.sonicstudies.org/vol01/nr01/a02 [consultat el 14.3.2015]

Urry, John (2000). Sociology Beyond Societies: Mobilities for the Twenty First Century. New York: Routledge.

Wolfe, Cary (2009). What Is Posthumanism? Minneapolis \& London: University of Minnesota Press. 